\title{
A mentira da verdade onto-teo-lógica: logos e areté em (per)formação
}

\author{
Lúcia Schneider Hardt* \\ Danilo JoséS Scalla Botelho \\ Rodrigo Mafalda**
}

\section{Resumo}

A formação ou paideia seria impensável sem outros dois conceitos, a saber: areté (excelência ou excelência política) e, sobretudo, logos (discurso). O objetivo deste artigo é, portanto, a partir do Prólogo e do capítulo $\mathrm{O}$ adivinho, da obra Assim falou Zaratustra, de Nietzsche, diferenciar genealogicamente dois tipos de logoi, que implicam distintas aretai (excelências políticas): um tipo onto-teo-lógico, ligado a alguma verdade incondicional, outro logo-lógico ou performático (sofista), em que se performam verdades condicionais. Tendo como pano de fundo a investigação de Bárbara Cassin acerca do "logos sofista" e como fio condutor o aforismo 1 de Ecce Homo, a hipótese é que Zaratustra, ao questionar uma verdade única onto-teo-lógica e admitir diferenciações, serve-se mais do logos performático - e "farmacológico", que cria realidades, no sentido de Protágoras - do que o santo e o adivinho. Questiona-se, desse modo, se as democracias e seus respectivos sistemas educativos contemporâneos (com os "partidos" inclusos) seriam suficientemente fortes para aceitar o tensionamento, a erística e a agonística, os nômades, a diferenciação, os que sobram, os que faltam, bem como outro(s) discurso(s) que não o hegemônico (ou "verdadeiro"), que representa "fielmente" o real. O povo não entendeu (o logos de) Zaratustra, preferiu o último homem. Hoje, o entenderia?

Palavras-chave: Areté (excelência). Logos. Nietzsche/Zaratustra. Sofista-performático.

Recebido: 05/03/2016 - Aprovado: 22/07/2016

http://dx.doi.org/10.5335/rep.v23i2.6539

Doutora em Educação pela Universidade Federal do Rio Grande do Sul. Professora associada da Universidade Federal de Santa Catarina. E-mail: luciashardt@gmail.com

** Doutorando em Educação no Programa de Pós-Graduação em Educação da Universidade Federal de Santa Catarina, subárea Filosofia da Educação, bolsista Capes. Professor convidado pelo Departamento de Educação da Universidade de Barcelona em 2016 e 2017. E-mail: danilojsb@hotmail.com

*** Doutorando em Educação no Programa de Pós-Graduação em Educação da Universidade Federal de Santa Catarina, subárea Filosofia da Educação. E-mail: mafalda.rodrigo2@gmail.com 


\section{Logoi (per)formados}

\section{Excelência política}

A areté, comumente traduzida por 'virtude', ainda que 'excelência política' seja mais literal, é o tema polêmico do diálogo platônico Protágoras, no qual Sócrates e o sofista Protágoras debatem se ela pode ser ensinada ou não. Para Bárbara Cassin, "[...] o modelo da excelência política não é senão, mais uma vez, o próprio logos (discurso)" (2005, p. 69). Protágoras defende não só que ela pode ser ensinada como também que ela é ensinada desde o momento do uso pela criança da convenção linguística que são as palavras, passando pela aprendizagem da leitura, escrita e música, culminando com o conhecimento da escrita que são as leis.

No famoso mito que Protágoras conta para ilustrar sua posição a Sócrates, a 'arte do fogo' que Prometeu rouba de Hefestos e Atena para conceder ao homem, a fim de suprir o desatino de Epitemeu que dividiu todos os dons (força, agilidade, proteção, visão ampla) entre os seres não falantes, embora faculte aos homens 'todas as facilidades para viver' (vestir-se, construir casas, cultivar a terra), não é suficiente para que convivam juntos sem injustiças. Falta-lhes, portanto, a arte política ou areté, para que possam permanecer juntos por mais tempo, sem injustiças, e ganhar as guerras contra animais ferozes. Zeus, preocupado com essa espécie em vias de extinção, envia Hermes, portador de aidos (vergonha ou 'respeito da opinião pública') e diké (justiça ou 'fazer valer o direito de cada um'), com a missão de reparti-los entre todos os homens (via instrução ou paideia ou formação), diferentemente das outras artes (as quais poucos possuem cada uma) e condenar à morte, como 'doença da cidade', os incapazes de partilhar isso.

O paradoxo protagórico pode ser visto assim: todos os homens ensinam a arte política tal como todos ensinam a falar a língua materna. Todos, sem exceção, da mesma maneira que falam, participam do político. "É o mito fundador da democracia" (CASSIN, 2005, p. 69). Mas alguns são melhores do que outros: por esse diferencial merecem ser escutados e reconhecidos. "É o mito fundador da aristocracia" (CASSIN, 2005, p. 69). Democracia e aristocracia, nesse viés, aparecem ligadas pela paideia (formação, educação). A velha questão platônica permanece e ganha outras roupagens: a quem seria melhor confiar a formação ou educação dos homens, ao filósofo-rei, que subjuga eticamente, ou ao mestre retórico-sofista, que desune ética e política, mas, simultaneamente, assegura a democracia? 


\section{Logos político e verdade}

Élio Aristides, no século II d.C., retoma o mito protagórico do diálogo platônico, alterando aquilo que Hermes traz à humanidade para que possa sobreviver civilizadamente: não mais aidos e diké, senão a retórica. Com ela, puderam desviar do caráter rude de suas vidas, deixando de incorporar a inimizade perante seus semelhantes, inaugurando os fundamentos de uma chamada "vida comunitária". Puderam construir, então, cidades bem como instituir os magistrados e as constituições, como ainda enviar aos deuses oferendas compostas de discursos. Dessa maneira, o homem se provê, de uma maneira sólida, de grandiosidade: de frágil e patológico que era a princípio, no começo menosprezado como uma criatura insignificante, estabelece-se desde então como maestro de tudo o que há na face da terra, possuindo legitimação para fazer o que bem quiser, tendo, para sua proteção, similar a um escudo, o discurso ou logos. Esse logos, diferentemente do logos onto-teo-lógico ou metafísico, não se comporta como um organon, representando ou dizendo o 'real' (de fora), mas, sim, - como Protágoras responde a Sócrates no diálogo platônico Protágoras - como um pharmakon, alterando (para melhor) os estados de espírito. É um logos que, em vez de rememorar o ser ou ter por tarefa dizê-lo, faz vir a ser como um efeito do dizer (CASSIN, 2005, p. 22, 85, 122).

A verdade mostra-se questão-chave entre as duas genealogias discursivas. No onto-teo-lógico, há uma verdade anterior que corresponde aos fatos e a tarefa do logos é dizê-la como é, representá-la fielmente, recordá-la. No "logo-lógico" ou sofista, não há uma verdade $a$ priori, pois não se tem acesso aos fatos (ou ao real) exatamente como eles são, pois na passagem de impulsos nervosos a imagens, de imagens a conceitos, de conceitos a palavras pronunciadas, dessas a imagens, dessas a conceitos, sempre há uma distorção ou metaforização (semelhança, analogia), jamais uma equivalência (identidade) exata. Nietzsche retoma perfeitamente esse argumento de base georgiana em Sobre a verdade e mentira em sentido extramoral. A verdade nesse logos, portanto, só pode ser pensada a posteriori, em função da força e do efeito discursivos. A enunciação também ganha espaço na logo-logia, enquanto o enunciado se impõe na onto-teo-logia.

\section{A verdade d'Ecce Homo}

Stegmaier, fazendo a análise contextual do aforismo 1 de Por que sou um destino (Ecce Homo), precisamente do trecho "- Mas a minha verdade é terrível, pois até agora chamou-se à mentira verdade. -" (NIETZSCHE, 2008, p. 102, grifo do autor), questiona-se: 
Que verdade pode falar a partir do crítico mais mordaz da verdade, que prefere ser um bufão a ser um santo? Certamente não a verdade metafísica, que prefere estar adequada a um ser fora dela - e com certeza também nenhuma que possa ser objeto de crença religiosa (STEGMAIER, 2010, p. 241-242, grifo nosso).

O narrador (Nietzsche) expõe a sua verdade, criada ou per-formada por ele. Sua performação brota a partir de um "descobrimento" (desnaturalização?) daquilo que até então valia, de forma 'mentirosa', como verdade. Ela não é expressa por travessões, de forma definitiva, mas deixada nas entrelinhas para ser deduzida (ou induzida, quiçá abduzida ou lida implicitamente) pelo leitor, sob sua própria responsabilidade: "a verdade como liberdade de decisão sobre a verdade ou a verdade como liberdade" (STEGMAIER, 2010, p. 244). Entretanto, essa liberdade de decisão mostra-se assombrosa, dado que não se sustenta em nada (sem a priori que a fundamente), podendo implicar empecilhos extremos e levar a uma total perda de orientação, a qual necessita ser enfrentada sem religião ou crenças, quer dizer, sem uma (única) verdade absoluta.

No evangelho de São João, Cristo afirma de si: "Eu sou o caminho, a verdade e a vida" (exemplo extremo de logos onto-teo-lógico). Nietzsche, em contrapartida, não escreve "Eu sou a verdade", mas, sim, "a verdade fala em mim": quando a verdade fala (importância da enunciação, não só do enunciado), ela também diz acerca de diferenciações, e em cada diferenciação, está presente também o outro lado da diferença, a outra alternativa possível (STEGMAIER, 2010, p. 246). Na verdade está o equívoco não desejado ou o engano (a mentira) desejado(a). A 'mendacidade' (desejada ou indesejada) de um santo (ou de um 'filósofo') reside na desqualificação da alternativa sempre possível. Desse modo, a verdade significa a decidibilidade da verdade pela afirmação de uma sua verdade, que, simultaneamente, exclui a possibilidade de que ela possa ser a mentira ou o erro (STEGMAIER, 2010, p. 250): "pois até agora chamou-se à mentira verdade" (NIETZSCHE, 1995, p. 11, grifo nosso).

A 'descoberta' da verdade imposta como única via, que implica (aparentemente) não haver outra alternativa - em outras palavras, do valor mais alto da metafísica, da moral e da religião ocidentais, que serve de fundamento a todos os valores restantes (STEGMAIER, 2010, p. 255) -, como sendo tão somente uma mentira, isso é a transvaloração de todos os valores, posto que ela não pode mais, diante desse "desvelar", ser uma "verdade" na concepção antiga, mas apenas uma "fórmula" (STEGMAIER, 2010, p. 260). 


\section{Os adivinhos políticos}

O adivinho - um dos "tipos" (e inclusive um dos homens superiores) na obra Assim falou Zaratustra (NIETZSCHE, 2011) -, após a 'morte de Deus' (consequentemente também a morte ou enfraquecimento do logos teológico cristão), é o personagem que incorpora a mera substituição de um discurso onto-teo-lógico por outro. Não mais apoiado em Deus, mas, sim, agora, no "grande cansaço", ele permanece ancorado em uma "verdade" prévia, como se correspondesse precisamente à realidade, para imputá-la aos outros. A força e o efeito desse logos são impressionantes, o que apenas uma perspectiva do logos como pharmakon, que leva em conta as outras (fora a referencial, relacionada ao assunto) dimensões de uma língua (a quem se fala e o que performa), pode notar. Para além da verdade ou falsidade do que o adivinho afirma (pois até Zaratustra se diz também "adivinho", embora não do grande cansaço), cabe perceber que efeitos performa nos outros e no mundo. A força e o efeito desse discurso valorizam a vida? Ele é, portanto, um pharmakon?

A separação, então, não é binária, como se houvesse discursos totalmente onto-teo-lógicos e outros totalmente logo-lógicos. A perspectiva de abordagem é que altera tudo, quando se veem os aspectos logo-lógicos (persuasivos e performativos) em um logos onto-teo-lógico e vice-versa, pois o que está em questão é que as duas 'outras' dimensões permaneceram subjugadas (ou mortificadas ou ignoradas ou escondidas) perante a dimensão 'apofântico-constativa' na tradição metafísica. Em uma visão de linguagem que considere as três dimensões presentes em qualquer língua fáctica, não apenas a dimensão apofântico-constativa; que veja uma dada linguagem como ato de fala na enunciação, não como mero enunciado; a ideia de verdade ou falsidade perde proeminência perante as noções de força e efeito. Ao fim de suas conferências (que posteriormente deram origem ao seu livro mais importante, How to do things with words), Austin confessa estar bastante inclinado a maltratar dois fetiches que "deixou em pedaços: o fetiche verdade/falsidade e o fetiche valor/fato" (AUSTIN, 1980, p. 151, tradução nossa).

\section{A insistência em ancorar um logos metafísico}

A educação é, em geral, um campo dos binarismos: à caça de um logos capaz de realizar com plenitude a formação humana e, por isso, sempre pronta para eliminar e excluir travessias indesejáveis. Se muitos educadores são caçadores desse logos, alguns sofrem de surtos de nomadismo. Apreciam o deslocamento, desejam ser tocados pelo sangue estranho, suportam o impacto da presença de muitos discursos. Nietzsche refere-se aos educadores como ineptos quando excessivamente 
concordatos, e o mais inepto dos educadores é ainda o moralista, que acredita que o bem só pode nascer do bem e crescer no bem. O binarismo é fruto dessa classificação entre o bem e o mal e impede o humano de jogar com o logos (e suas performações) enquanto o caça.

A quem seria melhor confiar a formação ou educação dos homens? Em que medida essa é uma tarefa de natureza política? Como educar e formar sendo avesso a essa caça compulsiva por uma ordem do discurso?

Para pensar a política e a impertinência dos dois logos que se apresentam como possibilidade da ação humana para jogar com os conceitos e valores estabelecidos, o texto deseja prosseguir operando com dois elementos inicialmente dissonantes: um personagem - o salsicheiro de Aristófanes - e um aforismo (305) de Nietzsche (2000), do livro Humano, demasiado humano.

O "salsicheiro" de Aristófanes, da obra Os cavaleiros (1985), é uma figuração, fala de uma nuance da política. Extraído da peça para jogar com o tema desse texto. Interessadamente. Na peça, está em questão o drama de uma cidade e a promessa e estratégia de um general - Demóstenes: fazer nascer um líder por meio de uma prática adulatória capaz de prometer e fazer acontecer. Cléon, apoiado pelo general, torna-se o preferido, aquele que arrebata todas as atenções, cativando o apoio incondicional das massas populares. Materializa-se um logos ligado a uma verdade incondicional, enfim, a mentira é tomada por verdade.

A comédia põe em cena a política por meio de vários recursos: o oportunismo de um líder, seu apetite voraz de domínio, de permanência, seu desejo de prestígio e a vontade de desfrutar dos bens públicos. Tendo cativado a maioria, então, o líder precisa fazer durar esse afeto para usufruir de toda sua vantagem. Instaura-se uma ardilosa relação entre aquele que idealiza a armadilha e quem por ela é capturado. Uma mentira transformada em verdade precisa de adeptos para então negociar interesses e proteção.

Cléon, o líder "feito", acaba contrariando até quem idealizou a estratégia de colocá-lo no poder. Como enfrentá-lo? Aristófanes, autor da comédia, precisará criar um personagem ainda mais imoral para enfrentar aquele que agora usufrui de toda a atenção. De um cenário caótico, surge um salsicheiro, mais vigarista que Cléon e capaz de enfrentar o impasse da unanimidade na política. Indagado sobre a oportunidade, o salsicheiro surpreende-se:

- Como eu, um salsicheiro posso tornar-me um senhor, estar na política?

- Precisamente nisso está sua oportunidade e grandeza: em seres um canalha, um vagabundo, filho de patifes, tens todas as qualidades para a vida pública.

- Não tenho instrução, sei apenas as primeiras letras.

- A política não é assunto para gente culta, e de princípios, é para ignorantes e velhacos. Não despreze o que os deuses agora te presenteiam (ARISTÓFANES, 1985, p. 178-194). 
O texto de Aristófanes mostra as habilidades do salsicheiro, apto para enfrentar Cléon e, por fim, receber o apoio da maioria. As nuances da peça são múltiplas e o seu fim é surpreendente, deságua em uma solenidade e festa desejando recordar outros tempos da política e de como é possível livrar-se de uma política sedutora. A mentira convertida em verdade sofre pressões e é o povo que, apesar de parecer inocente, também sabe persuadir, "morder o traiçoeiro pelo voto". Finge não ver a corrupção, mas de repente inverte o jogo e desmascara o líder.

No texto Os cavaleiros, a democracia também é retratada em números, a maioria significa o maior número de pessoas. Categoria conhecida da modernidade, mas já vivenciada no texto clássico. A suposta justiça da maioria. Quando desabrocha um logos pleno, ele vem acompanhado de unidade, de maioria, de crença, de convicção. A dissonância deve ser banida, qualquer produção de diferença é perigosa, está em questão estabelecer uma ordem, um discurso, um poder, uma crença.

Como anunciamos anteriormente, temos um segundo recurso para pensar a política e também a formação. Entra em cena Nietzsche: como ele nos faz pensar sobre política e também sobre a formação do humano? Tomaremos, prioritariamente, o aforismo 305 - Tática dos partidos, do livro Humano, demasiado humano.

Nietzsche foi um crítico da política, pois, em geral, ela esteve sempre circunscrita aos comandos daqueles que insistem com rebanhos. Nesse entorno, a lógica da maioria nos encaminha para os rebanhos, inclusive a democracia. Uma política revestida da pequena razão. Esse autor, nesse aforismo, nos faz pensar sobre a política tomando um recorte muito singular desse campo: o partido. Afirma que quando um adepto incondicional torna-se condicional, essa alteração de posição do indivíduo é pouco tolerada. Perante o fato de abandonar eventuais convicções, o partido sempre decide por produzir ofensas e provocações, preferindo afastar aquele que já não é mais incondicionalmente adepto. Prefere convertê-lo em adversário do que mantê-lo como um crítico dentro do partido. A política, no exercício do partido, prefere adversários que fazem oposição total do que aqueles que usufruem de um lugar no partido e escolhem ponderar, recusar, criticar.

As ferramentas de formação política são ambíguas, há todo tipo de prática adulatória, artifícios de prestígio, práticas de corrupção, cultivo de práticas diversas, dando à mentira e à verdade múltiplas definições. Educados que fomos a caçar um logos metafísico, ficamos impactados quando temos a oportunidade de confrontar esse logos com outro como o de Assim falou Zaratustra, percebemos como Nietzsche troca o céu pela terra.

Obviamente, não podemos com isso inferir que Zaratustra represente a crença de um paraíso na terra ou de que esse paraíso que é a terra tenha um modelo político ideal, tampouco que exista um logos absolutamente desprovido de embates. $\mathrm{O}$ 
logos de Zaratustra não foi compreendido pelo povo, apesar da terra. O povo quer um logos que represente o real, deseja um projeto ideal, pois não suporta alterar seu estado de espírito, prefere a fixidez e a segurança. Desejar segurança é um desdobramento da pequena política centrada em nacionalismos, imperialismos e a funesta confusão entre felicidade e segurança. $\mathrm{O}$ último homem deixa-se capturar por essa fórmula e insiste em formar-se com essa medida. $\mathrm{O}$ último homem aprecia estar entre a maioria. É o homem do rebanho, incapaz de suportar as diferenciações do espírito oriundas de uma vida intensa e agonística.

Então, a quem devemos destinar a tarefa da formação? O Zaratustra de Nietzsche indica várias alternativas, contudo, por fim, abandona essa preocupação para centrar-se em quem de fato suporta cultivar a si mesmo. O último homem é incapaz de suportar as adversidades e tudo troca, negocia em função dos prazeres e confortos. Torna-se desprezível, torna tudo pequeno e, infelizmente, é o homem que mais vive. Nasce a tirania da mediocridade, da uniformidade, consolida-se um tipo de democracia.

Segundo Giacóia (2013), a figura do "último homem" simboliza o alvo principal da crítica nietzschiana à modernidade política. Não estaríamos formando esse homem nas escolas? Em que medida a escola faz proliferar o "último homem"? Qual a saída?

Zaratustra distancia-se do povo retornando para o alto da montanha. Em um primeiro momento da obra, Zaratustra deixa a "praça pública" em busca de discípulos; todavia, ao final da obra, e na figura de um pescador de homens, Zaratustra encontra-se novamente na solidão da caverna. E mesmo recebendo ilustres visitantes - que servem como motivo de grandes interpretações, entre eles o "mendigo voluntário" e o "último papa" -, Zaratustra termina no alto da montanha e distante da praça. Seria necessário também abandonar as instituições educativas?

No Zaratustra, a maioria (a "praça pública"?) encanta-se com o último homem e confessa e pede: "dá-nos esse último homem, faz de nós esse último homem. O além-homem nós o presenteamos a ti, Zaratustra" (NIETZSCHE, 2007, p. 29). Não existe um entendimento entre o mestre e seus discípulos. O mesmo que, por vezes, ocorre na escola. Como continuar?

Talvez recusando um debate que insiste em produzir uma luta entre verdade e falsidade para, em seu lugar, "performar" discursos capazes de fazer proliferar a vida, fazer acontecer algo no mundo, muito mais que definir o que o mundo é - ou "deveria" ser.

Ao fazer algo com o mundo, aparece a cara cética do discurso. Surge a indagação, a boa pergunta, a ironia. Em geral, nossa tradição impede a dúvida e arranca uma verdade da mentira para fazer surgir um poder. $O$ cético nega-se a jogar nesse 
tabuleiro. E o próprio Nietzsche, em várias situações, escreveu sobre por que o cético era tão temido. $\mathrm{O}$ moralista tem excessiva seriedade sobre si mesmo, sobre seu discurso, sobre sua verdade. Não suporta o cético, pois ele não fica extasiado diante da virtude, quer pertencer a um campo e, simultaneamente, lutar contra o próprio campo. O cético incomoda a boa consciência, o sossego dos justos. Contudo, Nietzsche sabe do perigo dos próprios céticos, quando excessivamente protegidos pela sua própria crítica, "agasalham-se de sua virtude com a nobre abstenção" (NIETZSCHE, 1992, p. 112).

Larrosa, referindo-se a Nietzsche e sua abordagem sobre o ceticismo, nos ajuda a pensar a política:

A ética deve ser capaz de suportar a tensão entre fé e ceticismo. Contra a fé, o ceticismo mais corrosivo, o 'não!' mais implacável. Contra o ceticismo, a fé mais alta, o ideal mais puro, o 'sim!' mais voluntarioso. René Char o disse assim: "Fazer sonhar largamente a quem em geral não sonha, e submergir na atualidade aqueles em cujo espírito prevalecem os jogos perdidos de sonho" (2004, p. 202).

As medidas do adulador, do salsicheiro, do cético, do adversário, do crítico, da virtude, da ironia. A política enfrenta todo esse tipo de tempero. Vizinha da política, também a educação mergulha nessa experiência. Atacar as duas não significa tudo fazer desmoronar, tampouco tudo fazer conservar. Adentrar esse terreno implica suportar tensões próprias do campo da ação humana e, algumas vezes, fazer-se bálsamo, outras, veneno (ambas possíveis traduções de pharmakon). O suposto personagem de Aristófanes parece veneno quando sua aparição ocorre em função da necessidade de fazer desaparecer Cléon. Mais do que apreciar a suposta fragilidade moral do salsicheiro, caberia refletir sobre os efeitos que produziu no campo da política e se em alguma direção foi remédio. Larrosa (2004), referindo-se a Deleuze (Crítica e clínica, 1993), destaca a defesa que o filósofo faz da literatura como uma possibilidade de "escrever por esse povo que falta". Para Deleuze, o povo que falta está do lado da fábula, uma forma de invenção que interrompe a lógica da representação e assim interrompe uma linguagem autorizada a decifrar o que é modelo e o que é cópia.

Onde está esse povo que falta? Esse aluno que falta?

Segundo os autores referidos, a política não se reduz à arte do governo, mas acontece quando o "povo que falta" interrompe as regras, cria uma exceção, produz acontecimento. E o acontecimento pode nascer de um personagem, de um aforismo, conforme nosso exercício neste texto, tão somente para pensar a política para além dos generais, dos líderes aduladores, dos salsicheiros, dos partidos incapazes de suportar a crítica. Assim, quem sabe, sonhar largamente com um povo (ou pequenas singularidades) que falta $(\mathrm{m})$ e, paradoxalmente, existe(m) para criar outra políti- 
ca. De novo, uma espécie de nomadismo. Uma nova política exige outra cultura, menos massificadora e decadente. Nesses termos, Nietzsche não desvaloriza a política, contudo reconhece sua fragilidade quando está a serviço de uma massa que a tudo se submete por segurança. A moral cristã alcançou o Estado democrático e o resultado é decadência.

O ideário democrático está encharcado de uma moral, tributária de uma herança cristã, que nutre o animal de rebanho e, com isso, amolece e enfraquece o humano. Vontade popular, vontade da maioria são cuidados excessivos de quem apenas governa tendo em mente o presente. Nessa direção, depende da aprovação, do elogio. De fato, um estado faz política quando tem em seu governo a dimensão do futuro, ou melhor, quando sabe habitar o presente para provocá-lo em direção a outros rumos, menos decadentes. No aforismo 470 de Humano, demasiado humano, Nietzsche afirma que o político é “o lobo por trás da ovelha”. Precisa vestir a máscara do bom homem para caçar sua presa. Como afirma Delbó:

Mas enquanto o caçador devora o cordeiro que captura para saciar sua fome, o político, para conseguir governar, usa o cordeiro "para se esconder atrás de seu dorso lanoso" (MA I/ HH I 470, KSA 2.301). Isso não porque a desonestidade é inerente ao político, mas porque, na modernidade, somente com tais estratégias ele é aceito e bem avaliado. Não se trata de defender a impossibilidade de honestidade entre os políticos, mas de diagnosticar as "determinadas circunstâncias" nas quais o político tem a mesma necessidade de um homem honesto: quando precisa conseguir o que lhe é mais básico. No caso de precisar governar, a partir da concepção de soberania popular, ele deve atender à vontade do povo. Ao governo resta tentar lidar com os inúmeros, diversos e até inconciliáveis interesses daqueles que julgam permitir o poder - o que requer, portanto, vestir-se com a pele de um cordeiro. Somente as características do cordeiro são consideradas boas quando o único amparo da moralidade é a moralidade cristã (2013, p. 153-154).

A boa sociedade é aquela que tudo redime, conforta a todos, capaz de salvar a maioria em nome de uma promessa de bem-estar e proteção. Uma promessa que dificilmente se realiza, mas fica no horizonte para consolar o animal de rebanho. A política cultiva uma vítima para depois protegê-la, tal como a Igreja, que ao criar o pecado tem como propósito criar dispositivos para salvar o pecador. De acordo com a autora:

É esta a imagem que a Nietzsche repugna e que o faz denunciar os interesses existentes na política moderna: vontade de proteção, de cuidado, de vida cômoda, interesses típicos de seres debilitados que só podem pedir, reivindicar, exigir - seres, portanto, vitimados. E é contra essa tarefa que ele se coloca quando assume um distanciamento da política de sua época, mas não deixa de avaliá-la tornando evidente a moral que a degenera (DELBÓ, 2013, p. 154).

O movimento democrático, nesse contexto, é uma espécie de degradação: do homem e de sua força, já que sua inserção no ambiente democrático exige abrir 
mão de sua singularidade e potência. Já apontamos o quanto Nietzsche percebe esse movimento inclusive nos partidos e nas instituições formativas, já que eles preferem perder um militante, um estudante, do que suportar sua crítica. Trata-se de uma mediocrização do humano, um rebaixamento de sua potência. Nesses termos, a política que Nietzsche questiona é aquela que alimenta:

[...] debilidades humanas, [...] conduz adiante a fraqueza nos homens e, deste modo, compromete o futuro dos homens e da própria política, por fazer desta um mero dispensário da humanidade. Ao adotar princípios morais restritos e envenenadores do homem, a política tem o seu próprio funcionamento e objetivo reduzidos. Daí a aversão de Nietzsche pela política moderna enquanto propiciadora de experiências que somente atendem ao ímpeto de saciedade e de proteção. Se as exigências para a política se restringem à garantia de seguridade e paz, se tão somente a igualdade e o desinteresse por si são valores aceitos, todos os demais ímpetos humanos, rechaçados pela limitada moralidade moderna, carecem de condições de propagação. Neste sentido, o Estado torna-se instrumento para a diminuição e adoecimento do homem (DELBÓ, 2013, p. 156).

Assim, Nietzsche não pode ser definido como um pensador que rejeita a política, o que questiona é sua função exercida na modernidade, que supervaloriza o que amansa o homem, demonizando o que o faz indivíduo. $\mathrm{O}$ filósofo percebe isso tanto nas democracias quanto no socialismo e em outras formas de governo. Todos estão ancorados em sujeitos concordatos, submissos às promessas de justiça e segurança. Outra política poderá nascer de outra cultura, quando também a educação exigirá outros posicionamentos e inserções sociais.

$\mathrm{E}$ por que não pensar o além-homem como ruptura, também como um modo que tenha em vista o novo (outra natalidade/outra educação)? O além-homem como por-vir não é o homem como futuro, aquele já previsível e definido como possibilidade. Para Larrosa (2001), o "por-vir" é o contraponto do futuro. O por-vir é a relação com aquilo que não se pode antecipar nem prever, é o que escapa à medida de nosso saber, de nosso poder e de nossa vontade. O por-vir para sair de si, do que se é, do que se sabe, tem um sentido de interrupção para fazer parar um tempo linear e progressivo.

A arte de governar não é feita com total isenção, o que não se constitui em defeito, mas em pressuposto de uma atividade que é humana e, portanto, o cuidado e o amor de si não são prejudiciais à política. Limitar a política a um fim utilitarista, em que o que se dá e o que se recebe é sempre negociado, faz da política uma atividade menor. A grande política pode nascer quando sujeitos assumem o governo não cobertos de pele de cordeiro, mas se apresentam por inteiro, sem apelos adulatórios, altruístas, senão "de uma vontade de arte, de criações belas, criações humanas que não geram saciedade e estão liberadas da utilidade e da aprovação da maioria” (DELBÓ, 2013, p. 162). 
Vontade de arte oriunda de um logo-lógico, performático, em que se performam verdades condicionais com beleza e singularidade. Como já anunciamos, a força e o efeito desse logos são impressionantes, possibilitam a transvaloração de valores, movimento que se diferencia de uma disputa entre verdade e falsidade, para afirmar a vida, criar outra formação e, portanto, outra política.

\section{The lie of the onto-theo-logical truth: logos and areté in (per)formation}

\section{Abstract}

The "formation" or Paideia would be unthinkable without the other two concepts, namely: Areté (excellence or political excellence) and, above all, Logos (speech). The purpose of this article is, therefore, up the prologue and the Soothsayer's work "Thus spoke Zaratustra", by Nietzsche, to differentiate genealogically two kinds of Logoi, involving different Aretai (political excellencies): one onto-theo-logical, connected to some unconditional truth; another one, logo-logical or performative (sophist), in which conditional truths are performed. Having Barbara Cassin's investigation on the "sophist logos" as a reference, and the aphorism 1 Ecce Homo as a guiding line, we infer that Zaratustra, while questioning a single onto-theo-logic truth, considering differentiations, makes better use of a more performative, pharmacological logus, which creates realities in Protagoras' ways - than the Holy and the Forteller. In this way, we question whether democracies and their contemporary educational systems ("political parties" here included) would be strong enough to accept the tension, the eristic and agonistic, the nomadic elements, differentiation, those who are left behind, those who are missed, as well as other speeches than the hegemonic (or "true") one, which "faithfully" represents the real. People did not understand Zaratustra (and his logos), giving preference to the last man. Would people understand him (his logos) today?

Keywords: Arete (excellence). Logos. Nietzsche/Zaratustra. Sophist-performative.

\section{Referências}

ARISTÓFANES. Os Cavaleiros. Coimbra: Instituto Nacional de Investigação Científica, 1985.

AUSTIN, J. L. How to do things with words. 2. ed. Oxford: Oxford UP, 1980.

DELBÓ, A. Nietzsche: sobre alguns problemas morais da democracia moderna. Cadernos Nietzsche, São Paulo, n. 32, p. 149-166, 2013.

CASSIN, B. O efeito sofístico: sofística, filosofia, retórica, literatura. Tradução de Ana Lúcia de Oliveira, Maria Cristina Franco Ferraz e Paulo Pinheiro. São Paulo: Editora 34, 2005.

DURANT, W. Filosofia da vida. Tradução de Monteiro Lobato. São Paulo: Editora Nacional, 1956. v. 2. Livro 4.

GIACÓIA, O. Nietzsche: o humano como memória e como promessa. Petrópolis: Vozes, 2013. 
LARROSA, J.; SKLIAR, C. Habitantes de Babel. Belo Horizonte: Autêntica, 2001.

LARROSA, J. Linguagem e Educação depois de Babel. Tradução: Cynthia Farina. Belo Horizonte: Autêntica, 2004.

NIETZSCHE, F. Assim falou Zaratustra. Um livro para todos e para ninguém. Tradução de Paulo César de Souza. São Paulo: Companhia das Letras, 2011.

Humano, demasiado humano. Um livro para espíritos livres. Tradução, notas e posfácio de Paulo César de Souza. São Paulo: Companhia das Letras, 2000.

Ecce homo. Como alguém se torna o que é. Tradução de Paulo César de Souza. São Paulo: Companhia das Letras, 2008.

. Além do bem e do mal. Prelúdio a uma filosofia do futuro. Tradução de Paulo César de Souza. São Paulo: Companhia das Letras, 1992.

STEGMAIER, W. Nietzsche como destino da filosofia e da humanidade? Interpretação contextual do $§ 1$ do capítulo Por que sou um destino, de Ecce homo. Tradução de João Paulo Simões Vilas Boas. Revista Trans / Form /Ação, Marília, v. 33, n. 2, p. 241-278, 2010. 